\title{
Editorial: Staying the sustainability course during a pandemic
}

Cris B. Liban DEnv, PE

Chief Sustainability Officer, Los Angeles County Metropolitan Transportation

Authority, Los Angeles, CA, USA

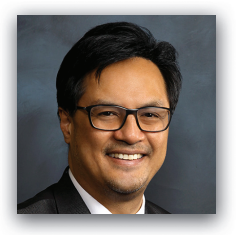

It is a sincere privilege and opportunity to be writing this month's editorial. I have been part of the Editorial Advisory Panel for a few months and have been fascinated with the information that I read, and the diversity of topics and perspectives in Engineering Sustainability.

The phrase 'engineering sustainability' means many things. In this month's issue, our authors tackle the overall theme of complying with or re-inventing sustainability. We explore here the challenge of one nation to achieve the UN Sustainable Development Goals (UN SDGs). We also read about how universities can be that powerful venue to implement, promote and create sustainable communities. On another front, we hear about how engineering and engineers should look for ways to build in resilience into projects and use life-cycle analysis as a way to prioritise sustainable strategies, meet project demands and maintain environmental benefits.

These are very timely articles. Considering the Covid-19 pandemic, many sustainability project proponents and public owners have struggled to maintain the level of expected engagement due to declining revenue streams. In fact, there are examples of jurisdictions here in California where their sustainability department was eliminated, and the remaining staff were distributed to other business units within the city.

That is not saying that the case for sustainability is lost or abandoned. Streamlining within those organisations may have led their policymakers to forego short-term gains on sustainability and resiliency, to respond to the immediate need to address complications related to the pandemic.

Even then, despite almost two decades of conversations and planning, there remains an obvious shortcoming on climate action. Yes, there have been many opportunities explored, and many countries around the world have poured in resources to protect, preserve or harden their assets and communities against the threat of climate change. These actions are currently not enough!

The article by Umar et al. (2020), entitled 'UAE's commitment towards UN Sustainable Development Goals', explores many of the efforts undertaken by even the richest countries in the Gulf Coast Council (GCC). Reflecting on the UAE government's commitment to meet the UN SDGs by 2030, the authors demonstrate the need to accelerate those efforts more aggressively. Multiple factors contribute to this.

What struck me most is the article's candidness on demonstrating how demographics and social relationships amongst those who live and work within the UAE had significantly impacted their ability to achieve the UN SDGs. That is not unique to UAE. I do not have to go far from where I live here in Los Angeles and I see similar patterns. What one will get out of Umar et al.'s article is an honest analysis and methodology on how one can assess their community's march towards sustainability. That candidness provides an unabashed call to action for the UAE, the GCC and the rest of the world who are struggling to achieve the UN SDGs, and to do so in the most innovative way. Close co-operation and collaboration would ensure equity in achieving the benefits of climate action between those who have the means and those who have not.

The preceding serves as a take-off point to look more closely at the sustainable and sustainability practices in institutions of higher learning. Umar (2020) in his article 'An integrated sustainabilitymanagement approach for universities' outlines an integrated approach to achieve sustainability in universities. He goes above that paradigm by explaining the university's implicit and explicit roles in advancing sustainability.

The duality of this approach is very novel. As institutions of higher learning conduct research on sustainability issues, they also act as catalysts for change, especially at those opportunities where the university implements in its capital and operational programs the principles it teaches. Those who are learning about sustainability experience sustainability on campus. Community stakeholders can use those innovations and implementation wins as ways either to advocate for sustainable infrastructure, or for project sponsors to develop the necessary comfort level to implement sustainable practices in infrastructure. 
Let's not forget the unintended consequence of this paradigm: development of leaders that would build sustainable and resilient infrastructure outside of the university setting. One would never know exactly how such a recommended best practice would influence those students, colleagues or community. One thing for certain, the university plays a pivotal role in sustainable infrastructure. Umar's paradigm is one way to frame that essential role.

The kind of influence the university provides using the above framework helps us understand further the need to re-engineer our practice. Students at universities learn how to think like an engineer and go through a rite of passage to become one. As an engineer myself, you and I know that we are bound by a commitment to 'hold paramount the safety, health and welfare of the public and shall strive to comply with the principles of sustainable development in the performance of their professional duties' (ASCE, 2017: p. 1).

Engineers are trusted voices in their communities. That engineering voice is relied upon very heavily by the community in the conduct and execution of civil infrastructure. However, our current practice of engineering is based on codes, standards and best practice that is founded on data that are assumed to have not foundationally changed. The wealth of historical empirical data combined with factors of safety have guided construction of infrastructure intended to be long-lived, safe, reliable and cost-effective.

The same wealth of information, specifically climate change data from the past decade, also tells us that the conditions upon which these assumptions are based have changed. With new models and new climate observations on the environmental effects on infrastructure and our communities, we are presented with a reality that the basis of our designs has changed and continues to change. It is imperative that we visit the 'how' of our practice. How do we adapt to a set of fundamentally different infrastructure design assumptions and conditions? How do we proceed with project development, design, procurement, construction, operations and maintenance, when all of the things we know are challenged by this changing environment?

In 'Fostering resilience-oriented thinking in engineering practice' by MacAskill et al. (2020), the best practices in planning/design/ construction/maintenance, governance, innovative and visionary project owners and sponsors, inter-jurisdictional collaboration and coordination, and community engagement comprise the major components to ensuring project resiliency. To that end, I also add that my fellow engineers should take on more leadership roles to ensure that our practice aligns with changed environmental conditions. Business-as-usual practices, frameworks and paradigms should be questioned and evolved.
Underlying all of this is our fiduciary duty to our clients, communities and stakeholders. Along with the project owners, we are ensuring that the built environment remains functional in the lifespan for which it is designed. This paradigm asks us to build projects sustainably. That is, build the right project and most importantly build the project right. That applies to essential structures like bridges.

Life-cycle analysis (LCA) is a tool where various elements of the bridge design can be analysed. In 'Life-cycle assessment environmental sustainability in bridge design and maintenance', Balogun et al. (2020) assert that LCA can provide an objective decision point on which sustainability strategies could make sense to implement within the project budget and schedule.

Finally, equity has been a big part of the recent conversations around the world. While the highest-profile examples of inequity come from the developed world, it would be remiss of me not to point out that equity in building the right project right should be the goal of every project owner, wherever those projects are. Sustainability is all about reducing the impacts of human activities wherever we are; but not everyone has their voice heard. The research work on our featured articles this month outlines many of those challenges and desired outcomes (including government intervention if need be), to make sure that those most vulnerable and impacted by human action are spared from the acute and chronic impacts of doing nothing in spite of exacerbated observed environmental impacts.

Until next time!

\section{REFERENCES}

ASCE (American Society of Civil Engineers) (2017) Code of Ethics. ASCE, Reston, VA, USA.

Balogun TB, Tomor A, Lamond J, Gouda H and Booth CA (2020) Lifecycle assessment environmental sustainability in bridge design and maintenance. Proceedings of the Institution of Civil Engineers Engineering Sustainability 173(7): 365-375, https://doi.org/10.1680/ jensu.19.00042.

MacAskill K, O'Hanlon F, Guthrie P and Mian J (2020) Fostering resilience-oriented thinking in engineering practice. Proceedings of the Institution of Civil Engineers - Engineering Sustainability 173(7): 356-364, https://doi.org/10.1680/jensu.19.00049.

Umar T (2020) An integrated sustainability-management approach for universities. Proceedings of the Institution of Civil Engineers Engineering Sustainability 173(7): 344-355, https://doi.org/10.1680/ jensu.19.00014.

Umar T, Egbu C, Ofori G et al. (2000) UAE's commitment towards UN Sustainable Development Goals. Proceedings of the Institution of Civil Engineers - Engineering Sustainability 173(7): 325-343, https://doi. org/10.1680/jensu.19.00036. 